\title{
Workplace Safety and Health Conditions and Facilities in Small Industries in Jeddah, Saudi Arabia
}

\author{
Ijaz Ahmad \\ Department of Environmental Science, Faculty of Meteorology, \\ Environment and Arid Land Agriculture, King Abdulaziz University, \\ P.O. Box 80208, Jeddah 21589, Saudi Arabia \\ Mansour A. Balkhyour \\ Department of Environmental Science, Faculty of Meteorology, \\ Environment and Arid Land Agriculture, King Abdulaziz University, \\ P.O. Box 80208, Jeddah 21589, Saudi Arabia
}

Tarek M. Abokhashabah

Vice Presidency of Projects, King Abdulaziz University,

Jeddah 80216, Saudi Arabia

Iqbal M. Ismail

Centre of Excellence in Environmental Studies (CEES), King Abdulaziz University, P.O. Box 80216, Jeddah 21589, Saudi Arabia

Mohammad Rehan (Corresponding author)

Centre of Excellence in Environmental Studies (CEES), King Abdulaziz University, P.O. Box 80216, Jeddah 21589, Saudi Arabia.

E-mail: dr.mohammad_rehan@yahoo.co.uk

Received: April 23, 2017 Accepted: May 4, 2017 Published: May 8, 2017

doi:10.5296/jss.v3i1.11104 URL: https://doi.org/10.5296/jss.v3i1.11104 


\section{Abstract}

A lot of attention has been paid to improving occupational safety and health (OSH) in small scale industries all over the globe. This study describes the outcomes of a preliminary OSH status assessment in small scale industries of motor vehicle repair workshops (MVRW) in Jeddah, Kingdom of Saudi Arabia (KSA). An inspection tool composed of $10 \mathrm{OSH}$ elements and 62 items employed walk-through survey, observations and interviews. The mean positive responses for different OSH elements surveyed were as follows; personal protective equipment (PPEs) (43\%), emergency preparedness (49\%), fire protection (60\%), facilities $(80 \%)$, general workshop safety (43\%), housekeeping (17\%), chemical exposure $(12 \%)$, services and maintenance (57\%), mechanical handling (81\%) and tool safety $(63 \%)$. However, special concerns were found for OSH elements including; use of PPE's, emergency preparedness, general workshops safety, housekeeping and exposures to chemicals as having safety score less than 50\%. OSH elements with lower positive responses at surveyed workshops would be addressed through further monitoring and training of technical and administrative staff. This preliminary survey will form the basis of a more comprehensive study for evaluation of an accurate representative OSH status in small scale industries in KSA.

Keywords: Safety and health, Occupational, Safety facilities, Safe work practices, Work environment, Jeddah

\section{Introduction}

Motor vehicles are essential part of today's life, their repair and maintenance has led to the emergence of a very large service sector industry also called workshops and garages. In some countries, this service sector industry is also categorized as informal, small and medium-sized enterprises (SMEs). It's a labor-intensive sector and the size of enterprise, its number of workers and their job function vary significantly [1,2]. A small business can be defined as non-manufacturing industries employing less than 20 employees and manufacturing industries with less than 100 employees [3]. There is an increasing attention all over the globe for improving occupational safety and health (OSH) in small sized enterprises. The main characteristics of the small enterprises are that they are operated and owned independently; closely controlled by managers/owners who contribute to the operating capital predominantly and are the principal decision makers [3].

Nearly 236,000 people work in 37,600 auto collision repair businesses in the US [NAICS code 811121 ]. A majority of these businesses (55\%) have four or less than four employees, $23 \%$ have 10 or more employees [4]. Workers encounter a wide variety of hazards, risks and exposures in this industry and the use of engineering controls and personal protective equipment (PPEs) have been well documented in this industry $[4,5]$ but other aspects of workplace safety including explosion and fire incidences, mechanical and electrical hazards, and the programs required to manage these hazards, are need to be explored further [4]. There is dearth of actual and reliable data available to public on number of workers in informal small repair workshops in Kingdom of Saudi Arabia (KSA). According to labor force survey 2016, total labor force work in the activity of whole sale trade, retail trade and vehicle repair 


\section{Macrothink}

(type of economic activity) is $18.4 \%$ of the total labor force [6]. Currently most of the OSH practices are not monitored thoroughly in KSA and many accidents in self-employed and small scale informal occupations went unreported [7].

In informal, small and self-employed industries like motor vehicle repair workshops (MVRW), workers lack awareness regarding routine chemicals and other hazards. Workers at such workplaces work in unhygienic conditions, daily exposed to fuels and don't use PPEs and other protective measures that can minimize skin cancer risk and respiratory ailments [7, 8]. MVRW employ a wide age range of workers and it's a tough sector to supervise and regulate in terms of OSH. Many research studies proved that workers in such small scale repair industries are more prone to work place hazards, risks and ill health effects [9] which can be somehow attributed toward less resources, low technical capacity, lack of knowledge and awareness regarding OSH guidelines. Many severe accidents happen which left victims paralyzed, loss of body parts reproductive, musculoskeletal disorders, skin diseases, neurological, psychological, mental and respiratory diseases $[9,10]$.

\section{Hazards in small vehicle repair and maintenance industries}

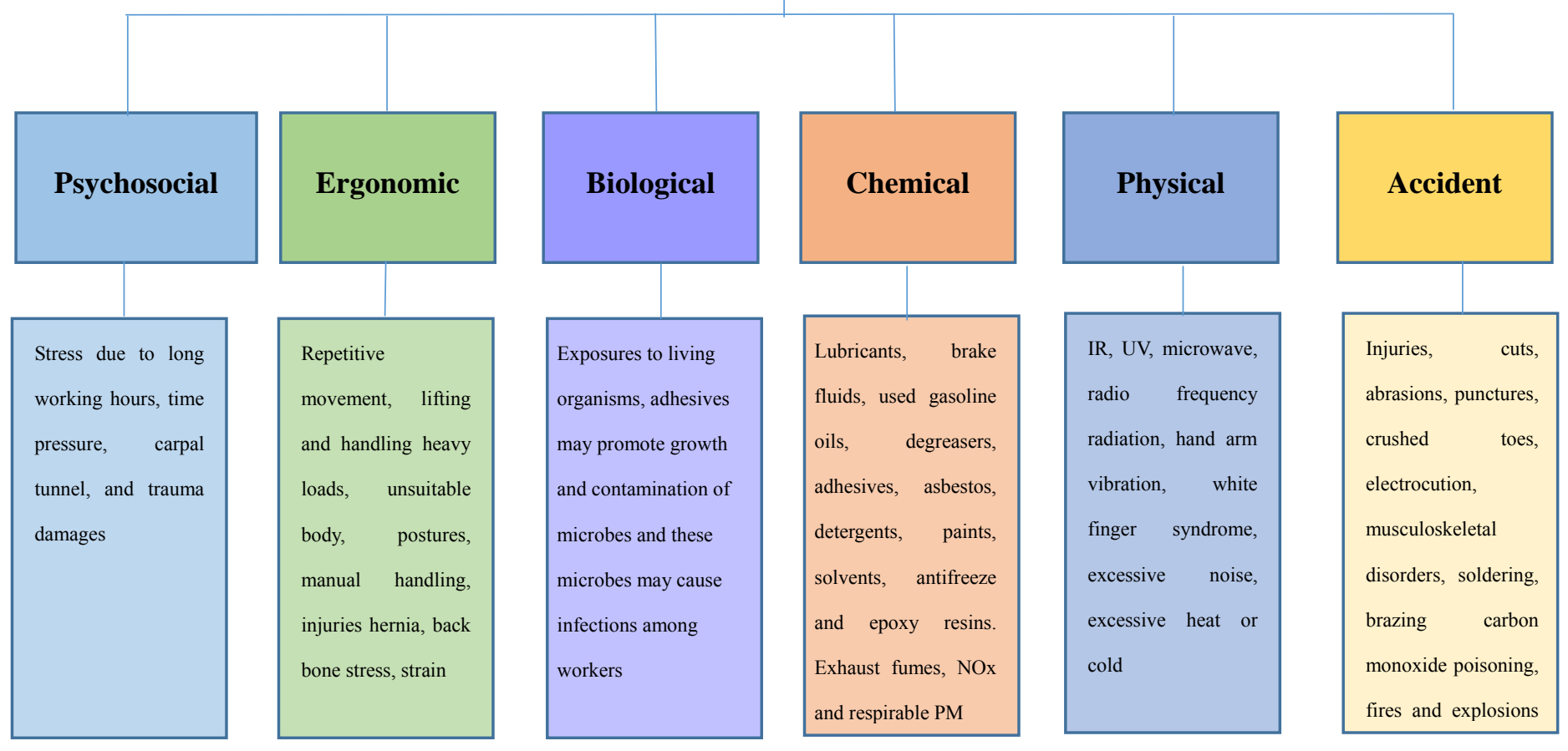

Figure 1. Flow chart for different types of hazards at small repair industries [7]

In KSA, extremely hot weather, majority of expatriate workers and their lack of OSH awareness and interest exposing them to a number of occupational hazards and risks, make 
MVRW sector a more vulnerable occupational group [7]. A detailed flow chart summarizing different potential physical, chemical, biological, accidental, ergonomics and psychosocial hazards are mentioned in figure 1. At MVRW, some dangerous practices like smoking, bad housekeeping, unhygienic clothes, working beneath vehicles, manual handling, lifting heavy loads, naked eye welding, eating and drinking are a matter of daily life. These practices and such workplace hazards cause adverse health effects like respiratory ailments, acute injuries, eyes injuries, hearing loss, musculoskeletal disorders [2, 4].

The current study was conducted to assess the OSH practices, conditions, facilities and environment in the MVRW in Jeddah for the first time. An inspection tool, composed of 10 OSH elements and 62 items, was designed and employed walk-through survey, observations and interviews. OSH data was collected from 13 selected sites and individual and mean positive responses were reported for each item and element respectively. The areas of concerns were highlighted and recommendations given for further improvements. The outcome of this study will help to conduct further more comprehensive OSH studies in small scale industries in KSA.

\section{Methodology}

\subsection{Study Area}

KSA has witnessed highest urban, economic and infrastructure development in previous decades. Due to sandy deserts, background air pollution especially dust and PM level is very high throughout the year especially when wind blows from nearby sandy areas to inhabited city areas [11]. Jeddah is the second largest industrial and developed city of KSA, with an estimated population of around 4.03 million $[12,13]$. Jeddah is the main gate of pilgrimage and visitors to KSA, situated at Eastern Coast of the Red Sea at Latitude $29.2^{\circ}$ North and Longitude $39.7^{\circ}$ East [14]. It is said to be a car dominated city, at present there are around 18 million registered vehicles in KSA [15], 70 thousand fuel stations and thousands of small industries for repairing and maintenance of motor vehicles employing thousands of workers [7].

\subsection{Local Conditions}

Dust storms, obstructive buildings, arid environment, exhaust emissions, extremely hot summers, energy generation from fossil fuels, construction works, humidity, wearing and tearing of tires on roads, less herbs/plantation are common features of the local environmental and atmosphere [16 - 20]. Recent studies have proved exceeding levels of PM in Jeddah than the standards of PME (KSA) and EPA (US) [21 - 23]. One special characteristics in KSA is that majority of labor force especially in informal small scale sectors here is expatriate. A previous study in small vehicle repair service industry in KSA proved that almost all the workers working in this industry are expatriates [24].

Most of the MVRW in Jeddah employ around 3-10 workers including welders, electricians, mechanics, spray painters, panel beaters etc. MVRW workers spend around 8 to 12 hours per day and the local hot weather and worker's little OSH awareness and safety precautions make them more vulnerable. In particular, exposure to exhaust fuels, dusts, particulate matters and 
chemical fumes are of more health concerns as reported earlier [7].

\subsection{Survey Checklist}

We designed and prepared the study survey checklist items based on different workplace OSH assessment checklists, survey reports, publications, local and international regulatory rules and regulations [Civil defense, KSA, US EPA, OSHA, National Fire Prevention Code (NFPC)]. For survey tool preparation, input was also sought from academic and field OSH professionals, suppliers, workshops supervisors, mechanics and local regulators as per local conditions and applicability.

After preliminary testing in five small representative industries some items were excluded and some extra were included in the checklist. The final checklist covers assessment comprising $62 \mathrm{OSH}$ questions grouped into 10 components/elements.

1. Personal protective equipment (7 items)

2. Emergency preparedness (3 items)

3. Fire protection (4 items)

4. Facilities (6 items)

5. General workshop safety (11 items)

6. Housekeeping (4 items)

7. Chemicals exposure (8 items)

8. Service and maintenance (10 items)

9. Manual handling (2 items)

10. Tool safety (7 items)

The answers for each item/question were in the form of Yes (item is present, compliance with regulation, meeting best practice), NO (if any item is incorrect, missing, deficient, against regulations, not meeting best practice) and if the question does not apply, the answer was not applicable (NA). Each "Yes" indicates best/good activity/practice/condition for workers health and safety and each "No" indicates unsafe and unhealthy activity/practice/condition. For each "No" specific recommendation for making it "Yes" was written in the comments column against that item and was briefed to supervisors as well as workers to adapt it.

\subsection{Industries Inclusion Criteria}

20 MVRW in Jeddah were randomly selected after visiting them. An introduction and participation invitation letter was obtained from the department of Environmental Sciences and the Faculty of Meteorology and Environment, King Abdulaziz University, Jeddah KSA and presented to the selected MVRW's representatives. 7 workshops refused to participate after learning the survey details, therefore we surveyed the remaining 13 workshops. The recruitment method included referrals from the initially agreed workshops' supervisors and some known suppliers and workers at the workshops. The method was time consuming but systematic as repeated phone calls and personal visits had to be made. The study was conducted through November to December 2015. The selected participants were briefed about aims and objectives of research and assured regarding confidentiality of their particulars. 
The research survey was conducted at each selected MVRW site by two occupational hygienist professionals. A supervisor or manager was interviewed for safety and health documents, rules and policies, demographics of workshops and number of employees. The workplace conditions and other items (PPEs, lights, access aggress paths, fire extinguishers, physical condition of gas cylinders, tools, electrical cords, floors, exposure to chemicals, dusts, oils etc.) presence were assessed through the walk through survey, personal observations and visual inspection. Employees were interviewed about safe use of machinery equipment and use of PPEs. During survey, workers were briefed regarding observations, but the checklist was not made open and workplace interviews were made at the end.

\section{Results and Discussion}

The OSH practices, conditions, facilities and environment was assessed in 13 selected MVRW in Jeddah through comprehensive survey study. An inspection tool composed of 10 OSH elements and 62 items employed walk through survey, observations and interviews for the study. The first element of the survey study of PPEs availability and use showed a low average positive response of only $43 \%$ with standard deviation (SD) of 17.94 . The highest positive response of $62 \%$ was reported for the provision and usage of knee and joint protection mats, whereas the lowest positive response of $23 \%$ and $15 \%$ reported for foot protection worn as required and hearing protection used when required, respectively (Table 1).

Table 1. Results summary for evaluated personal protective equipment in studied MVRW

\begin{tabular}{|c|c|c|c|}
\hline \multirow{2}{*}{ Personal protective equipment } & \multicolumn{3}{|c|}{ \% Responses $\quad(\mathrm{N}=13)$} \\
\hline & Yes & No & Not applicable \\
\hline Safety glasses and/or goggles used as needed? & 54 & 46 & 0 \\
\hline Hearing protection utilized when required? & 15 & 85 & 0 \\
\hline Hand protection used/worn as required? & 54 & 46 & 0 \\
\hline Foot protection worn as required? & 23 & 77 & 0 \\
\hline Face masks are used/worn as needed? & 54 & 46 & 0 \\
\hline $\begin{array}{l}\text { While welding helmet, gloves, apron, and } \\
\text { curtain used as needed? }\end{array}$ & 38 & 46 & 16 \\
\hline $\begin{array}{l}\text { Knee \& Joint protecting mats are present and } \\
\text { used? }\end{array}$ & 62 & 38 & 0 \\
\hline Mean \pm SD & $43 \pm 17.94$ & $55 \pm 18.24$ & $2 \pm 6.00$ \\
\hline
\end{tabular}

Provision of proper PPEs is the responsibility of the employer under the Saudi labor law 2005 (Royal Decree M/51, dated 23/08/1426) as amended in 2015 by resolution 258. Workshop workers occasionally exposed to loud sounds for extended lengths of time which can effect hearings especially for older workers. The Université de Montréal study proved that mechanics are exposed to noises that are more than 90 decibels. According to another study, 
at vehicle repair industry noise output of various tools i.e. air hoses, electric grinders, pneumatic grinders and chisels, and sanders all produce sounds louder than 100 decibels [25]. The low positive response of PPE element in our study was due to the unavailability of PPE in some case but mostly because of the workers unawareness of its importance or simply not used due to uncomfortable feeling. A similar type of study in the small industries in Alkhober KSA was conducted in year 2000 which revealed that only $12 \%$ of the workers used PPE's all the time, whereas $60 \%$ did not use any available PPEs at all [24].

The summary results for the safety element of emergency preparedness were found to be relatively higher as the mean positive result was $49 \%$. It included three safety items namely emergency contact numbers displayed, cleared access and egress paths and availability of approved first aid kit (Table 2). In terms of health and safety, emergency preparedness is very important for any workplace to tackle any untoward situation. One of key concepts for effective emergency response is "preparation" [26]. The poorest response in this study was noted for the availability of first aid kit. As only $15 \%$ on average of selected small industries had appropriate first aid kit available, despite the fact that working in auto workshops is full of hazards and risks specially injuries, cuts, bruises and burns [7]. According to a previous Saudi study in small vehicle repair industries, many workplace hazards were identified, injuries and accidents were the major ones (39\%) reported by workers [24].

Table 2. Results summary for evaluated emergency preparedness in studied MVRW

\begin{tabular}{lccc}
\hline Emergency preparedness & \multicolumn{2}{c}{ \% Responses } & $(\mathrm{N}=13)$ \\
\cline { 2 - 4 } & Yes & No & Not applicable \\
\hline Emergency contact numbers prominently displayed? & 54 & 46 & 0 \\
Access and egress paths clear? & 77 & 23 & 0 \\
Approved first aid kit available? & 15 & 85 & 0 \\
\hline Mean \pm SD & $49 \pm 31.34$ & $51 \pm 31.34$ & $0 \pm 0.0$ \\
\hline
\end{tabular}

Table 3. Results summary for evaluated fire protection in studied MVRW

\begin{tabular}{lccc}
\hline Fire protection & \multicolumn{2}{c}{ \% Responses } & $(\mathrm{N}=13)$ \\
\cline { 2 - 4 } & Yes & No & Not applicable \\
\hline Fire extinguishers and sand buckets readily & 77 & 23 & 0 \\
available (not blocked)? & 77 & 23 & 0 \\
Workers trained in using fire extinguishers? & 31 & 69 & 0 \\
Smoking prohibited in work area & 54 & 46 & 0 \\
Rubbish and flammable substances are stored & & & $0 \pm 0.0$ \\
Separately? & $60 \pm 22.02$ & $40 \pm 22.02$ & 0 \\
\hline Mean \pm SD & & & \\
\hline
\end{tabular}


The results of next safety element of fire protection in this study showed good positive mean response of $60 \%$ with SD of 22.02. Among the all safety items in this category, fire extinguishers and sand buckets readily available (not blocked) as well as workers trained in using fire extinguishers both items showed the highest positive response of $77 \%$ (Table 3). It can be attributed toward the vigilance of the monitoring agencies and good Saudi building code practices adherence. The lowest positive response of $31 \%$ was observed for the smoking in work area for this OSH element.

The provision of facilities element received one of the highest mean positive response of $80 \%$ with SD 11.51 in this study. The drinking water facility item, water coolers were available at the studied sites for workers, was ranked the highest with $92 \%$ in this element, attributed to generosity of the local people. Moreover, the facilities items of toilets, shadow and proper exhaust and ventilation systems also scored very high positive response of $85 \%$ (Table 4 ). Even the lowest positive response of $62 \%$ in this category for availability of air conditioners is good enough. The provision of all such facilities is also mandatory under Saudi labor law 2005.

Table 4. Results summary for evaluated facilities in the studied MVRW

\begin{tabular}{|c|c|c|c|}
\hline \multirow{2}{*}{ Facilities } & \multicolumn{3}{|c|}{$\%$ Responses $\quad(\mathrm{N}=13)$} \\
\hline & Yes & No & Not applicable \\
\hline Rest areas provided? & 69 & 31 & 0 \\
\hline Toilets and accessible? & 85 & 15 & 0 \\
\hline Drinking water facility accessible? & 92 & 8 & 0 \\
\hline $\begin{array}{l}\text { In case open work amid hot weather, } \\
\text { shadow provided? }\end{array}$ & 85 & 15 & 0 \\
\hline Air conditioner available & 62 & 38 & 0 \\
\hline $\begin{array}{l}\text { Proper exhaust and ventilation system } \\
\text { (toxic vapors such as carbon monoxide } \\
\text { and other solvents) exist? }\end{array}$ & 85 & 15 & 0 \\
\hline Mean \pm SD & $80 \pm 11.51$ & $20 \pm 11.51$ & $0 \pm 00$ \\
\hline
\end{tabular}

The mean positive results for general workshop safety element was found to be low i.e. $43 \%$ (Table 5). This indicates that only $43 \%$ of vehicle repair industries studied followed safe practices and procedures according to the general workshop safety guidelines. The general observations amongst most workshops studied were that floors were uneven, cluttered with oily rags, work benches were not properly cleaned and most of the working area had fuel and other chemical odors etc., thus scored below 30\% for these items. The safety guidelines for no food and drinks in the working area was not followed at all in all studied sites. Moreover, other crucial OSH visual aids, signs, symbols, slogans present also scored only $23 \%$ positive response. This clearly indicates the need of more similar studies across different industry 
sectors in KSA. In addition, workers training in OSH as well as strict protocols to ensure the implementation of these crucial OSH guidelines for the safety of the workers is needed. Many researches endorsed that providers recognize the extraordinary need for preparing and delivering OSH information. According to an Australian study in small metal industry, exposure to hazards were found above permissible values and access to OHS information was poor by immigrant and low level literate workers [3].

Table 5. Results summary for evaluated general workshop safety in studied MVRW

\begin{tabular}{lccc} 
& \multicolumn{2}{c}{$\%$ Responses } & (N=13) \\
\cline { 2 - 4 } \multicolumn{1}{c}{ General workshop safety } & Yes & $\begin{array}{c}\text { Not } \\
\text { applicable }\end{array}$ \\
\hline $\begin{array}{l}\text { Workshop floors in good condition, smooth and are } \\
\text { free from obstacles? }\end{array}$ & 8 & 92 & 0 \\
All areas have adequate illumination? & 100 & 0 & 0 \\
$\begin{array}{l}\text { Appropriate cans/bins/container available for } \\
\text { disposing off oily rags, metal rubbish and flammable }\end{array}$ & 31 & 69 & 0 \\
liquids? & & & \\
Work benches are neat and clean? & 15 & 85 & 0 \\
$\begin{array}{l}\text { Heavy goods, materials stored in appropriate } \\
\text { racks/shelves designed for load bearing purposes? }\end{array}$ & 38 & 62 & 0 \\
Temperature in working area is comfortable? & 100 & 0 & 0 \\
Working area is free from odor? & 23 & 77 & 0 \\
Food/ drinks are not allowed in the work area? & 0 & 100 & 0 \\
Are vehicles always braked and chocked? & 100 & 0 & 0 \\
No pedestrians are passing front/back of vehicles & 38 & 62 & 0 \\
OSH visual aids, signs, symbols, slogans present & 23 & 77 & 0 \\
\hline Mean \pm SD & $43 \pm 38.20$ & $57 \pm 38.20$ & 0.00 \\
\hline
\end{tabular}

The performance of selected sites in terms of housekeeping element was also found to be very low. On average only $17 \%$ of studied workshops had good housekeeping in terms of spill free, smooth neat and cleaned floors and immediate cleanup for spillages. The worst results found for the safety item of chemical spills containment facility provide, where none of the studies sites had proper containment facility for chemical spillage (Table 6). Again, the poor results of housekeeping element indicates the need of awareness and training of all staff, especially the technical workers to not only understand the OSH guidelines and protocols but give importance in their implementation. 
Table 6. Results summary for evaluated housekeeping in studied MVRW

\begin{tabular}{|c|c|c|c|}
\hline \multirow[t]{2}{*}{ Housekeeping } & \multicolumn{3}{|c|}{$\%$ Responses $\quad(\mathrm{N}=13)$} \\
\hline & Yes & No & Not applicable \\
\hline Floors are free from oil, grease/ water spillage? & 15 & 85 & 0 \\
\hline General housekeeping is neat and orderly? & 31 & 69 & 0 \\
\hline Fluid and water spillages cleaned up immediately? & 23 & 77 & 0 \\
\hline Chemical spills containment facility provided? & 0 & 100 & 0 \\
\hline Mean \pm SD & $17 \pm 39.50$ & $83 \pm 39.50$ & $0 \pm 00$ \\
\hline
\end{tabular}

The mean positive response for the safety element of chemical exposure was found to be the poorest among all safety elements in this study, only $12 \%$ mean positive response was reported at all studied sites. Unsafe practices and conditions like exposure to paint, diesel, gasoline and used gasoline engine oil (UGEO) fumes was observed at all surveyed workshops (Table 7). These unsafe acts, practices and unhealthy working environment is very dangerous for occupational health of the studied population. Many epidemiology studies proved that inhalation and ingestion of gasoline among mechanics causes lead poisoning and even death [27]. Hands and forearms exposure to mineral oil and hydraulic fluids can develop weakness in them [28]. Direct contact with fuels and lubricants causes acne, dermatitis, skin sensitization and eczema [29]. The freely use of gasoline among workshop workers is due to some misconceptions, as according to a research in Ilorin, workers believed that such fuels are not harmful when taken in small doses instead these can actually act as a cleansing [30].

Table 7. Results summary for evaluated chemicals exposure in studied MVRW

\begin{tabular}{lccc}
\hline Chemicals exposure & \multicolumn{2}{c}{ \% Responses } & (N=13) \\
\cline { 2 - 4 } & Yes & No & Not applicable \\
\hline $\begin{array}{l}\text { Workers don't expose to chemicals while } \\
\text { painting vehicle? }\end{array}$ & 0 & 46 & 54 \\
$\begin{array}{l}\text { Workers not expose to diesel, gasoline fumes } \\
\text { while degreasing, repairing engine or parts? }\end{array}$ & 0 & 61 & 39 \\
Workers not expose to UGEO? & 15 & 46 & 39 \\
$\begin{array}{l}\text { Batteries (lead acid, Ni-cad, silver, etc.) } \\
\text { managed for recycling? }\end{array}$ & 0 & 39 & 61 \\
Waste oils stored and disposed of ppropriately? & 46 & 54 & 0 \\
All chemical containers labeled appropriately? & 23 & 77 & 0 \\
Gasoline is not used to clean parts? & 0 & 100 & 0 \\
Workers know chemical safety of chemicals? & 15 & 85 & 0 \\
\hline Mean \pm SD & $12 \pm 16.34$ & $64 \pm 21.66$ & $24 \pm 26.78$ \\
\hline
\end{tabular}


The mean positive response for another important safety element of service and maintenance was found to be of satisfactory level of $57 \%$. These surveyed sites had safe and healthy working environment and conditions and were following good OSH practices in this regard (Table 8). The maximum positive results of $85 \%$ were observed for three safety and health items; compressors guarding in place and serviced regularly, air pressure used for cleaning is discharged at no more than $30 \mathrm{psi}$, and bench grinder wheel is guarded \& securely fastened. The lowest positive response of $15 \%$ and $22 \%$ were reported for OSH item of acid carboys are available and OSH items of gas cylinders lacking obvious defects, leaks and damage as well as gas cylinders stored in a safe, well ventilated place, respectively.

Table 8. Results summary for evaluated Service and maintenance in studied MVRW

\begin{tabular}{lccc}
\hline Service and maintenance & \multicolumn{2}{c}{ N Responses } & (N=13) \\
\cline { 2 - 4 } & Yes & No & $\begin{array}{c}\text { Not } \\
\text { applicable }\end{array}$ \\
\hline Gas cylinders, valves, couplings, regulators kept free of & 38 & 38 & 24 \\
oil and grease? & & 54 & 24 \\
Gas cylinders lacking obvious defects, leaks and & 22 & & \\
damage? & & 54 & 24 \\
Gas cylinders stored in a safe, well-ventilated place? & 22 & 15 & 0 \\
Compressors guarding in place and serviced regularly? & 85 & 15 & 0 \\
Air pressure used for cleaning is discharged at no more & 85 & 31 & 0 \\
than 30 psi? & & 23 & 0 \\
Spark plug cleaner is in good condition & 69 & 0 & 15 \\
Parts are cleaned in dip tank? & 77 & 31 & 0 \\
Bench Grinder wheel is guarded \& securely fastened? & 85 & & \\
All lifting equipment (chains, slings, jacks) serviced, & 69 & 85 & 0 \\
maintained and in good condition? & & 15 & $8 \pm 11.52$ \\
Acid carboys are available? & $57 \pm 29.08$ & $35 \pm 24.56$ & \\
\hline Mean \pm SD & & & \\
\hline
\end{tabular}

The results for the safety element of manual handling were good, the mean positive response was found to be $81 \%$ with SD of only 5.65 (Table 9). It comprised of investigating that either mechanical aids for lifting and carrying heavy and bulky items i.e. tires, engine parts, gas cylinders etc. were provided, assistance for moving, pushing, pulling heavy and bulky items was available. During the work at workshops, employees are around tools and bulky equipment, often lifting items which can cause musculoskeletal problems. Furthermore, they spend long time in working in bent position, lying on their back and such other awkward postures. The workers at workshop especially mechanics often work with various tools, so the appropriate and safe tools can play an important role in the OSH of the workers. The 
mean positive response of our inspection study for the safety element of tool safety was found to be $63 \%$ with SD of 18.55 (Table 10). The maximum safe act of $85 \%$ was found for the use of safety jacks while working under vehicle, whereas the lowest positive response of $31 \%$ was found for safety item of presence of warning labels on tools, equipment/ appliances.

Table 9. Results summary for evaluated manual handling in studied MVRW

\begin{tabular}{lccc}
\hline Manual handling & & \% Responses & (N=13) \\
\cline { 2 - 4 } & Yes & No & Not applicable \\
\hline $\begin{array}{l}\text { Mechanical aids provided/used for lifting, } \\
\text { carrying heavy/ bulky items; tires, batteries, gas } \\
\text { cylinders, engine blocks? }\end{array}$ & 85 & 15 & 0 \\
$\begin{array}{l}\text { Is assistance for moving, pushing, pulling heavy } \\
\text { or bulky items available when required }\end{array}$ & 77 & 23 & 0 \\
\hline Mean \pm SD & $81 \pm 5.65$ & $19 \pm 5.65$ & $0 \pm 0.0$ \\
\hline
\end{tabular}

Table 10. Results summary for evaluated tool safety in studied MVRW

\begin{tabular}{lccc}
\hline Tool safety & \multicolumn{2}{c}{ \% Responses } & (N=13) \\
\cline { 2 - 4 } & Yes & No & $\begin{array}{c}\text { Not } \\
\text { applicable }\end{array}$ \\
\hline Safety jacks used while working under vehicles? & 85 & 15 & 0 \\
Portable power tools provided with guarding? & 69 & 31 & 0 \\
$\begin{array}{l}\text { Double insulated or grounded power tools used? } \\
\text { Hand tools are in good condition, (hammers, } \\
\text { wrenches, striking tools, etc.) }\end{array}$ & 62 & 38 & 0 \\
$\begin{array}{l}\text { Impact air tools have safety clips or retainers on } \\
\text { them? }\end{array}$ & 46 & 23 & 0 \\
$\begin{array}{l}\text { Stepladder or stepstool used for high access? } \\
\text { Warning labels/instructions on equipment's, }\end{array}$ & 31 & 69 & 31 \\
tools/appliances present? & $63 \pm 18.55$ & $33 \pm 17.57$ & $4 \pm 11.71$ \\
\hline Mean \pm SD & & 31 & 0 \\
\hline
\end{tabular}

Lot of attention has been paid for improving occupational safety and health in small scale industries all over the globe. This study for the first time, showed outcomes of a preliminary OSH status assessment in small scale industries of MVRW in Jeddah, KSA. Many similar studies reported that most small scale industries' managers, employees have little knowledge and awareness of OSH and give low priority to it. The lack of awareness for multiple hazards in such working conditions and low importance to implement OSH practices can potentially 
cause serious health problems to workers [30]. For example, eating and drinking habits were found in almost all of the studied sites. Similar findings have been reported by a Nigerian study, where eating and drinking was reported as very common habit among auto mechanics and they rarely wash their hands properly before eating. This unhygienic habit expose the workers to auxiliary risks [31].

Many studies suggested that the OSH unsatisfactory outcomes in small scale industries might be due to a commonly held perspective among owners that OSH relies mostly on employee actions. Interestingly managers and owners agreed that they had an obligation for providing a healthy and safe work conditions and PPE's, but they also believe that most of the responsibility for safety resides with workers [4]. To minimize exposure to noxious workplace agents like loud noises, dust, smoke, fumes, and poor working postures low cost approaches should be formulated i.e. implementing engineering controls (e.g., proper ventilation), encouraging the use of personal protective equipment's.

This study was a preliminary assessment of OSH status in 13 selected MWRV in Jeddah and may not represent the true OSH status in this industry. There are certain limitations in this study that need further investigation and analysis. It is possible that selected workshops may have higher than average levels of interest and practices in OSH. At the same time, it is also possible that workers at some sites may have had cleaned up operation before assessment as the visits were scheduled, which would effect on the accuracy of the results. Nonetheless, unscheduled visits are generally not an acceptable approach in the local cultural as well as governmental and managerial rules and practices. Furthermore, seasonal variation can also effect survey results in terms of the provision and need for facilities to employees which vary significantly in summer and winter in KSA. A more detailed survey study is under progress by authors and will be published in another article after completion. More comprehensive similar studies are needed in MVRW and other small industries in order to understand the situations and gaps for improvement of OSH in such industries in KSA.

\section{Conclusion}

This study describes the outcomes of a preliminary OSH status assessment in small scale industries of 13 selected MVRW in Jeddah, KSA. The designed survey was based on $10 \mathrm{OSH}$ elements and 62 items employed walk-through survey, observations and interviews. 5 OSH elements received good mean positive responses including; fire protection (60\%), facilities $(80 \%)$, services and maintenance (57\%), mechanical handling (81\%) and tool safety $(63 \%)$. However, 3 OSH elements showed below average positive responses in between $40-50 \%$ including; PPEs (43\%), emergency preparedness (49\%), general workshop safety (43\%). The 2 most concerning OSH elements were found to be the housekeeping and chemical exposure, which scored only $17 \%$ and $12 \%$, respectively. OSH elements with lower positive responses at surveyed workshops would be addressed through further monitoring and training of technical and administrative staff. There is a requirement for a conceptual framework for interventions in this industry sector. Our preliminary results suggest that such small scale industries could benefit from training, consultation assistance, intervention programs and awareness workshops. 


\section{Acknowledgements}

This article was funded by the Deanship of Scientific Research (DSR) at King Abdulaziz University, Jeddah. The authors therefore acknowledge with thanks DSR for technical and financial support. We are thankful to all workshop workers, managers, and other study participant for their cooperation, time and thoughtful comments.

\section{References}

[1] Heer, V. Y. A. S., Subir, D. A. S., Mehta, S. (2011). Occupational injuries in automobile repair workers. Industrial health, 49, 642-651. https://doi.org/10.2486/indhealth.MS1294

[2] Caldwell, D. J., Armstrong, T. W., Barone, N. J., Suder, J. A., Evans, M. J. (2000). Hydrocarbon solvent exposure data: compilation and analysis of the literature. AIHAJ-American Industrial Hygiene Association, 61, 881-894. https://doi.org/10.1080/15298660008984602

[3] Seneviratne, M., Phoon, W. O. (2006). Exposure assessment in SMEs: a low-cost approach to bring OHS services to small-scale enterprises. Industrial Health, 44, 27-30. https://doi.org/10.2486/indhealth.44.27

[4] Brosseau, L. M., Bejan, A., Parker, D. L., Skan, M., Xi, M. (2014). Workplace safety and health programs, practices, and conditions in auto collision repair businesses. Journal of occupational and environmental hygiene, 11, 354-365. https://doi.org/10.1080/15459624.2013.866714

[5] Velázquez, L., Bello, D., Munguia, N., Zavala, A., Marin, A., Moure-Eraso, R. (2008). A survey of environmental and occupational work practices in the automotive refinishing industry of a developing country: Sonora, Mexico. International journal of occupational and environmental health, 14, 104-111. https://doi.org/10.1179/oeh.2008.14.2.104

[6] LFS (Labor force survey 2nd quarter 2016, General Authority for Statistics) https://www.stats.gov.sa/sites/default/files/so-lfs-06-2016-en_2.pdf

[7] Ahmad, I., Rehan, M., Balkhyour, M., Abbas, M., Basahi, J., Almeelbi, T., Ismail, I. M. (2016). Review of Environmental Pollution and Health Risks at Motor Vehicle Repair Workshops Challenges and Perspectives for Saudi Arabia. International Journal of Agricultural and Environmental Research, 2, 1-23. http://www.ijaaer.com/papers/1458636802.pdf

[8] Kamal, A., Cincinelli, A., Martellini, T., Palchetti, I., Bettazzi, F., Malik, R. N. (2016). Health and carcinogenic risk evaluation for cohorts exposed to PAHs in petrochemical workplaces in Rawalpindi city (Pakistan). International journal of environmental health research, 26, 37-57. https://doi.org/10.1080/09603123.2015.1007843

[9] Adei, E., Adei, D., Osei-Bonsu, S. (2011). Assessment of perception and knowledge of occupational chemical hazards, in the Kumasi metropolitan spray painting industry, Ghana. Journal of Science and Technology (Ghana), 31, 83-94. https://doi.org/10.4314/just.v31i2.69397 
[10] Punnett, L., Wegman, D. H. (2004). Work-related musculoskeletal disorders: the epidemiologic evidence and the debate. Journal of electromyography and kinesiology, 14, 13-23. https://doi.org/10.1016/j.jelekin.2003.09.015

[11] PME, 2012.Presidency of Meteorology and Environment, The Royal Kingdom of Saudi Arabia (http://www.pme.gov.sa/en/en_airpollution.asp).

[12] Saudi Gazette http://saudigazette.com.sa/saudi-arabia/jeddah-jubail-expats-saudis/ (accessed on 26th March 2017)

[13] IBI, G. (2007). Jeddah public transportation study. Ministry of Transportation, Saudi Arabia.

[14] Jeddah Economic Gateway, Jeddah guide facts and figures. Jeddah Chamber of Commerce and Industry. Available online: http://www.jeg.org.sa/data/modules/contents/uploads/infopdf/1090.pdf/ (accessed on 20 January 2017)

[15] Vehicle on Saudi roads. http://www.arabnews.com/news/648791 (accessed on 20 January 2017)

[16] Munir, S., Habeebullah, T. M., Mohammed, A. M., Morsy, E. A., Rehan, M., Ali, K. (2016). Analysing $\mathrm{PM}_{2.5}$ and its association with $\mathrm{PM}_{10}$ and meteorology in the arid climate of Makkah, Saudi Arabia. Aerosol and Air Quality Research. https://doi.org/10.4209/aaqr.2016.03.0117

[17] Ouda, O. K. M., Raza, S. A., Nizami, A. S., Rehan, M., Al-Waked, R., Korres, N. E. (2016). Waste to energy potential: a case study of Saudi Arabia. Renewable and Sustainable Energy Reviews, 61, 328-340. https://doi.org/10.1016/j.rser.2016.04.005

[18] Miandad, R., Rehan, M., Nizami, A. S., Barakat, M. A. E. F., Ismail, I. M. (2016). The energy and value-added products from pyrolysis of waste plastics. Recycling of Solid Waste for Biofuels and Bio-chemicals (pp. 333-355). Springer Singapore. https://doi.org/10.1007/978-981-10-0150-5_12

[19] Nizami, A. S., Ouda, O. K. M., Rehan, M., El-Maghraby, A. M. O., Gardy, J., Hassanpour, A., Ismail, I. M. I. (2016). The potential of Saudi Arabian natural zeolites in energy recovery technologies. Energy, 108, 162-171. https://doi.org/10.1016/j.energy.2015.07.030

[20] Nizami, A. S., Shahzad, K., Rehan, M., Ouda, O. K. M., Khan, M. Z., Ismail, I. M. I., Demirbas, A. (2017). Developing waste biorefinery in Makkah: a way forward to convert urban waste into renewable energy. Applied Energy, 186, 189-196. https://doi.org/10.1016/j.apenergy.2016.04.116

[21] Basahi, J. M., Ismail, I. M., Hussain, H. K., El-Behaedi, E. H., Hassan, I. A. (2015). Air Pollution Assessment in Fuel Stations and its Impact on Workers' Health: a Case Study from Jeddah, KSA. Adv. Environ. $\quad$ Biol, $\quad 9, \quad 326-331$. https://www.researchgate.net/publication/285138079 
[22] Hussein, T., Alghamdi, M. A., Khoder, M., AbdelMaksoud, A. S., Al-Jeelani, H., Goknil, M. K., Hämeri, K. (2014). Particulate matter and number concentrations of particles larger than $0.25 \mu \mathrm{m}$ in the urban atmosphere of Jeddah, Saudi Arabia. Aerosol and Air Quality Research, 14, 1383-1391. https://doi.org/10.4209/aaqr.2014.02.0027

[23] Khodeir, M., Shamy, M., Alghamdi, M., Zhong, M., Sun, H., Costa, M., Maciejczyk, P. (2012). Source apportionment and elemental composition of PM 2.5 and PM 10 in Jeddah City, Saudi Arabia. Atmospheric pollution research, 3, 331-340. https://doi.org/10.5094/APR.2012.037

[24] Taha, A. Z. (2000). Knowledge and practice of preventive measures in small industries in Al-Khobar. Saudi medical journal, 21, 740-745.

[25] Bejan, A., Brosseau, L. M., Parker, D. L. (2011). Exposure assessment in auto collision repair shops. Journal of occupational and environmental hygiene, 8, 401-408. https://doi.org/10.1080/15459624.2011.585117

[26] Health and Safety Executive (UK): Health and Safety in Motor Vehicle Repair and associated industries. HSG 261, HSE Books, 2009, ISSBN 9780717663088

[27] Anetor, J. I., Babalola, O. O., Adeniyi, F. A. A., Akingbola, T. S. (2002). Observations on the haematopoietic systems in tropical lead poisoning. Niger. J. Physiol. Sci., 17, 9-15. http://hdl.handle.net/1807/7924

[28] Agency for Toxic Substances and Disease Registry (ATSDR) (1997). Toxicological profile for hydraulic fluid, Atlanta, Georgia, USA

[29] ILO (1998). Encyclopedia of Occupational Health and Safety, $4^{\text {th }}$ Ed., ILO. Geneva.3:102.26-102.32

[30] Awoyemi, A. O. (2002). Awareness about occupational hazards among roadsides auto mechanics in Ilorin, Nigeria. Journal of Community Medicine \& Primary Health Care, 14, $27-33$

[31] Johnson, O. E., Bassey, E. A. (2016). Work Habits and Health Problems of Automobile Technicians at Mechanic Village, Uyo, Nigeria. Global Advanced Research Journal of Medicine and Medical Sciences, 5, 136-142. http://garj.org/garjmms

\section{Copyrights}

Copyright for this article is retained by the author(s), with first publication rights granted to the journal.

This is an open-access article distributed under the terms and conditions of the Creative Commons Attribution license (http://creativecommons.org/licenses/by/4.0/) 